\title{
Influence of Gender on the Advertising Responses of Young People for Products of Mobile Operators in Bulgaria
}

\author{
Lyubomira Spasova ${ }^{1 *}$, and Tanya Taneva ${ }^{1}$ \\ ${ }^{1}$ Department of SSBLT, Faculty of Economics, Trakia University, Bulgaria
}

\begin{abstract}
The use of gender as a marketing strategy for market segmentation requires consideration of gender differences in information processing. This would increase the effect of advertising campaigns by adapting them to the dynamically changing market. he presented empirical study was conducted after 300 men and women aged 18 to 25 years, users of functional mobile products. The aim of the study is to determine the extent to which gender determines positive and negative advertising responses, identifying subjective judgments. The results of the research are empirical confirmation of some basic hypotheses of the Selective model of information processing in advertising messages: objectivity in the processing of information by men and subjectivity in the processing of information by women; selectivity in the perception of the attributes of the product by men and integrity - by women and a stronger willingness to use new products by women than by men. The present study offers an empirical hypothesis that women form positive responses to a larger number of signals in advertising, while men form negative responses to a larger number of signals in advertising messages. Satisfaction is proving to be a very important factor in advertising responses for both sexes, as it is a stronger factor for women, and men's frustration with a mobile product is stronger than for women.
\end{abstract}

\section{Introduction}

Due to the pressure on gender neutrality, in recent years there has been a tendency in company ads to be universal for both sexes. Ignoring the differences in the way men and women process information often leads to the exclusion of one sex altogether, halving the achievement of targeted advertising impact [1]. The importance of the problem is growing as the world has changed dramatically in recent decades. The number of educated, financially independent women is growing, they are increasingly able to make their own decisions about investments and purchases [2-[3], they become an increasing percentage of the workforce, and some of them start new businesses [4]. Sheehan [4] refers to the study "Marketing to Women Quick Facts", 2011 [5] presents facts that women buy or influence the purchase of $85 \%$ of all consumer goods.

* Corresponding author: liubomira1975@abv.bg 
By targeting ads and products to gender, companies adapt to the changing market to increase the impact of their marketing campaigns $[1,3]$. Despite the practical importance of gender in the determination of consumer behavior, research on gender differences is scarce [6]. Using gender as a market segmentation strategy has the following advantages: (1) easy to identify, (2) gender segments are accessible, (as most media provide information) (3) gender segments are measurable, and (4) gender segments are large enough to be profitable [6-8]. There are also few meta-analyzes available, showing comprehensive summary information on the importance of gender differences in advertising, which would provide new conceptualizations of marketing problems [7, 9-10]. Researchers have found evidence of some clear differences between men and women that need to be taken into account when designing marketing campaigns $[7,1]$. The general thesis is that men and women have different views on advertising, and it can be assumed that men and women derive different meanings from the advertisements they see.

The present study differs from the others in this thematic area first, in that it examines the influence of gender in product advertising in a specific economic sector - mobile services, which is almost not found in the research literature; second - allows gender comparison in both positive and negative response to advertising messages from young users.

\section{Theoretical Background}

\subsection{Models for gender differences in the processing of information from advertisements}

For decades, research has sought to outline the main similarities and differences between the sexes in how consumers feel, think, process, and behave as a result of advertising influences, which is essential for effective advertising solutions [7], [11]. There is theoretical and empirical evidence of differences in the strategies by which men and women process advertising information or in their preferences to process different types of advertising. It is important for advertisers to understand them in order to make effective promotions for each segment [6].

Arcand and Nantel compare the two popular models predicting gender differences in information processing [12]. The Selectivity Model [13] assumes that women put more effort into overall understanding than men who selectively focus on a particular type of information, while the Item-Specific / Relational Processing Model or IS / RP model [14] suggests that men and women differ mainly in their processing style, with men tending to use specific processing by focusing on product attributes, and women tending to use relational processing, looking for relationships between many different parts of the information. Basing the discussion on a number of studies [12, 15-19], Arcand and Nantel [12], emphasize that according to the Selectivity Model [13]: men are selective processors, focusing on easily accessible, instrumental attributes of products and services, and women are complete processors, willing to engage in detailed, complex and diligent information processing, with a focus on interpersonal relationships, belonging and attachment to others [12]. To compensate for the lack of integrity, men tend to use heuristics that serve as substitutes for more detailed processing, such as focusing on highly accessible information that stands out in the context [12].

In contrast, Putrevu's IS / RP model [2001] [14], (according to [12]) argues that men are specific processors for specific attributes of articles that are distinctive for a brand or product, and women are relational processors that tend to look for interconnections and similarities between multiple signals $[12,20]$. As both models have received support in different marketing contexts, Arcand and Nantel [12] concludes that there is a degree to which these 
models complement each other, but the data still provide more support for the selectivity model than the IS / RP model [12].

\subsection{Objectivity vs. subjectivity in information processing}

There is empirical evidence that men and women respond differently to objective and subjective advertising messages [21]. Men are focused on solving problems, focusing on the task [1], which is why they attach the greatest importance to the benefits and functionality of the product and are focused on satisfying immediate or short-term needs and desires. They prefer objective messages presenting physically tangible attributes of the product that can be directly perceived or specific data that can be measured with a standard scale that is not subject to individual interpretation - price, speed, and others. Women, on the other hand, take into account not only the functionality, but also the subjective impressions of intangible attributes of the products (which have no physical reality - elegant, stylish, impressive), as well as the emotional context in the product advertisement. [3, 6, 21-26]. strive to satisfy long-term needs and desires. As long as there are gender differences, it can be predicted that men will respond more positively to objective advertisements and women will respond more positively to subjective advertisements. As a result of these differences, men are often described as more analytical and logical in their orientation and information processing, while women are characterized as more subjective, emotional, interpretive, and evaluative [6, 27], which Putrevu's IS / RP model [2001] [14] calls into question [6]. In addition, women are more sensitive to discrepancies in the marketing message and are more likely to respond to advertisements that contradict their experience with the product. [3, 28]. Gender differences are also observed in groups of people with special educational needs [47].

\subsection{Selectivity vs. integrity in information processing}

The main hypothesis for selectivity according to Wolin [7] is the difference in the processing of advertising information between men and women, in which women are considered complete information processors that assimilate all available signals, while men are considered selective information processors that assimilate only the obvious signals [6-7, 13, 29]. When they make sense of advertising, men focus on the main message (for example "buy this product") [4]. Women not only appreciate the main message, but also extract many signals from the message and process them together to intuitively extract the inner meaning of the message (for example "Buy this product and you will be fashionable") [4, 30]. When using the meaning of advertising, men process messages with a focus on tasks and make decisions faster than women, in a linear style of thinking and reasoning, concentrate on the main message of an ad and receive almost no other information during the process [4]. They use the elimination strategy as a decision-making tool - they decide which aspects of the product are most important and eliminate products that do not have these attributes, i.e. eliminate competing products. Heuristics that men use as substitutes for detailed information processing usually involve a cue sign, which is very accessible, subordinate to the focal context and implies a single conclusion [6] Women, on the other hand, use more comprehensive decision-making methods. They process information in advertising at many levels and from a variety of sources, including music, visuals, voice, and text. They tend to evaluate and weigh the different sources in order to process the message and determine what steps to take next [4]. Processing processes in women are less task-oriented than in men, characterized by gradual thought processes in which each piece of information is based on previously accepted information [4] This non-linear approach to reasoning allows women to integrate all elements before making a decision, to think about interrelated factors in messages with low congruence, and not in a straightforward way and in a scheme and by 
elimination, as in men $[31,4,7]$. Thus, women treat information that is relevant to themselves and information about others relatively equally [6] Darley a. Smith [6] specifies that women can: (1) encode more advertisements than men and / or (2) further develop advertising messages more extensively. In addition, based on a summary of numerous studies, Wolin [7] commented on the fact that repetitive advertising exposure is more effective for women. Single advertising exposures may not be enough to create a sustainable advertising response in women as opposed to men. There is also a suggestion that, in general, women are less consistent with a particular brand and are more likely to look for a relatively lower price, while men, regardless of price, are more likely to buy a product based on the brand.

The origin of these gender differences is a complex issue, with biological and social aspects [12, 19, 25, 32], summarized in the theory of biosocial origin [33]. In general, the hypothesis is evolutionary - physical differences define the social roles of men and women: hunting and protection for men and family care for women [12]. Accordingly, the style of information processing by men, with their focus on achievement, making, self-focus, and competitiveness, corresponds to the dominant social role they have played in evolutionary terms. In contrast, women who have traditionally been in a subordinate position learn to survive by being attentive to the fin signals from other people and the environment [12]. Biological basis is widely discussed differences in the brains of men and women, [34, 32].

\subsection{Information processing for fine informational signals / cues}

Men and women also differ in the extent to which they notice subtle information signals [6$8,13,29,35-36]$. Women are expected to be more likely to notice e.g., the difference in perceived product risk or product innovations, and to adequately adjust their information processing strategies $[6-8,36]$. Men, as selective processors, are more likely not to notice subtle differences in product risk or novelty, as and not change their message processing strategy, even if they notice subtle differences, as they will continue to rely on accessible and visible focal cues [6]. A logical consequence is the more common preference for women to try new brands and products, while men more often prefer to stick to well-known brands. It can be said that the selectivity model predicts a significant three-way interaction between gender, objectivity of messages and the level of perceived product risk / openness to product novelty [6].

\section{Research Design and Methodology}

The study involved 300 respondents aged 18 to 25 years, of whom $67 \%$ - women and $33 \%$ men. They are all consumers of functional mobile products according to the differentiation of Darley and Smith [6]: products that express values and functional products.

The main purpose of the present study is to determine the extent to which gender determines positive and negative advertising responses, and to identify the subjective judgments that determine the advertising responses of the respondents.

Based on the theoretical framework and the purpose of the study, the following hypothesis is stated: Gender influences the advertising response in the perception of advertisements of young people using mobile products and services.

Based on the theoretical framework and the purpose of the study, the following hypothesis is stated: Gender influences the advertising response in the perception of advertisements of young people using mobile products and services.

An anonymous structured survey was conducted to conduct the survey. The questionnaire consists of 25 items, some of which are composite, examining the subjective judgments of the respondents about the advertisements of the mobile operator whose products they use. In 4 open questions they can supplement their opinions with emic type of information. For the 
remaining closed questions, a three-level Likert-type scale is applied, expressing the degree of agreement with the proposed statements. The study presents data on subjective evaluations of elements of advertising that provoke positive and negative advertising response, only in which there are statistically significant differences in gender.

To establish the factor structure of the questionnaire, factor analysis with rotations by Warimex was applied. Four factors are derived: two for a positive advertising response - in relation to the product and in relation to the company and 2 for a negative advertising response - in relation to the product and in relation to the company. Two factors will be presented in this publication: First factor: "Positive product response"; Second factor: "Negative product response".

Table 1. Factor structure of Factors "Product response".

\begin{tabular}{|c|c|c|}
\hline Factor structure & $\begin{array}{c}\text { 1 Factor } \\
\text { Cronbach's } \\
\text { Alpha - 0.79 }\end{array}$ & $\begin{array}{c}\text { 2 Factor } \\
\text { Cronbach's } \\
\text { Alpha - 0.81 }\end{array}$ \\
\hline $\begin{array}{c}\text { The advertisement informs about the attributes of the } \\
\text { product }\end{array}$ & 0.89 & \\
\hline Advertising is done through product demonstrations & 0.67 & 0.70 \\
\hline Entertaining nature of product advertising & 0.76 & 0.83 \\
\hline Satisfaction with the using of products & 0.71 & 0.63 \\
\hline $\begin{array}{c}\text { The advertisement does not provide complete product } \\
\text { information }\end{array}$ & & 0.81 \\
\hline The advertisement does not present the qualities of the \\
product well
\end{tabular}

Statistical processing of the results was performed by Pearson regression and correlation analysis, Student-Fisher t-test, Warimex rotation factor analysis (SPSS statistical analysis package).

\section{Results}

The results of the regression analysis show a statistically significant influence of gender on the subjective assessments of the respondents on the components of both factors: Positive and negative advertising response to the product, as in both factors the strongest influence is the impressions of product use - satisfaction $(\beta=0.74, \mathrm{p}<0.001)$ and frustration $(\beta=0.67, \mathrm{p}$ $<0.001$ ), (Table 2).

Table 2. Influence of gender on advertising responses.

\begin{tabular}{|c|c|c|c|c|c|}
\hline $\begin{array}{c}\text { Independent } \\
\text { Variable }\end{array}$ & Dependent Variable & $\boldsymbol{\beta}$ & $\Delta \mathbf{R 2}$ & $\mathbf{p}$ & St. Dev \\
\hline$\dot{\bar{g}}$ & \multicolumn{5}{|c|}{$\begin{array}{l}\text { Positive advertising response } \\
\end{array}$} \\
\hline تֶّ" & $\begin{array}{l}\text { The advertisement informs about the } \\
\text { attributes of the product }\end{array}$ & 0,61 & 0.62 & 0.001 & 0.67 \\
\hline
\end{tabular}




\begin{tabular}{|l|c|c|c|c|c|}
\hline \multirow{1}{*}{} & $\begin{array}{c}\text { Advertising is done through product } \\
\text { demonstrations }\end{array}$ & 0.46 & 0,42 & 0.05 & 0.59 \\
\cline { 2 - 6 } & Entertaining nature of product advertising & 0.56 & 0,52 & 0.001 & 0.52 \\
\cline { 2 - 6 } & $\begin{array}{c}\text { Satisfaction with the use of the same or } \\
\text { similar product }\end{array}$ & 0.74 & 0,81 & 0.000 & 0.64 \\
\cline { 2 - 6 } & $\begin{array}{l}\text { Negative advertising response } \\
\text { The advertisement does not provide } \\
\text { complete product information }\end{array}$ & 0.40 & 0,31 & 0.000 & 0.70 \\
\hline $\begin{array}{c}\text { The advertisement does not present the } \\
\text { qualities of the product well }\end{array}$ & 0.53 & 0,17 & 0.000 & 0.52 \\
\hline $\begin{array}{c}\text { The advertisement is meaningless / } \\
\text { incomprehensible }\end{array}$ & 0.47 & 0,46 & 0.002 & 0.65 \\
\hline & Disappointment with the purchased product & 0.67 & 0.56 & 0.000 & 0.62 \\
\hline Dependent Variable: Advertising response \\
\hline Predictors: (Constant), Gender
\end{tabular}

\subsection{Influence of gender on positive advertising responses}

According to the selective model of information processing, men are statistically significantly more influenced by the objectively presented attributes of the products in the advertisements of a mobile operator, compared to women $(\bar{x} 1=2.56)$, who are generally less attracted by the presentation of the attributes of the product in the advertisement (Table 3 ). The opposite direction of gender influence on the advertising response as a result of product demonstrations as a form of advertising, which causes a statistically significantly more positive response from women $(\overline{\mathrm{x}} 2=2.35)$, compared to men $(\overline{\mathrm{x}} 1=2.17)$, Table 3 . In addition, women $(\overline{\mathrm{x}} 1=2.37)$ were statistically significantly more positively influenced by the entertainment nature of mobile operators' advertisements than men $(\overline{\mathrm{x}} 2=2.26)$. The study also found another interesting fact: Pearson correlation analysis showed that for all respondents, regardless of gender, the positive response to entertainment effects in advertising is strongly proportional to the positive response to product satisfaction $(\mathrm{R}=0.72$, $\mathrm{p}<0.05)$. In addition, women's satisfaction $(\overline{\mathrm{x}} 1=2.27)$ with the use of mobile products elicited a statistically significantly stronger positive response to advertisements for the same product than men $(\bar{x} 2=2.09)$, (Table 3$)$. Women's satisfaction with the use of mobile products is described in the open-ended questionnaire questions through experiences such as happiness, joy, and pleasure, while men describe their satisfaction with the use of the product with statements such as "I'm happy" and "doing a good job".

Table 3. Influence of gender on positive advertising responses.

\begin{tabular}{|c|c|c|c|}
\hline Dependent Variable & $\begin{array}{c}\text { Independent } \\
\text { Variable }\end{array}$ & $\overline{\mathbf{x}}$ & t \\
\hline $\begin{array}{l}\text { 1. The advertisement informs about the attributes of } \\
\text { the product }\end{array}$ & $\begin{array}{l}\text { Female } \\
\text { Male }\end{array}$ & $\begin{array}{l}2.54 \\
2.72\end{array}$ & $\begin{aligned} & \mathrm{t}=3.35 \\
& \mathrm{p}<0.01\end{aligned}$ \\
\hline 2. Advertising is done through product demonstrations & $\begin{array}{l}\text { Female } \\
\text { Male }\end{array}$ & $\begin{array}{l}2.39 \\
2.17\end{array}$ & $\begin{array}{l}\mathrm{t}=2.95 \\
\mathrm{p}<0.05\end{array}$ \\
\hline 3. Entertaining nature of product advertising & $\begin{array}{l}\text { Female } \\
\text { Male }\end{array}$ & $\begin{array}{l}2.37 \\
2.26\end{array}$ & $\begin{array}{l}\mathrm{t}=3.14 \\
\mathrm{p}<0.01\end{array}$ \\
\hline $\begin{array}{l}\text { 4. Satisfaction with the use of the same or similar } \\
\text { product }\end{array}$ & $\begin{array}{l}\text { Female } \\
\text { Male }\end{array}$ & $\begin{array}{l}2.09 \\
2.27\end{array}$ & $\begin{array}{l}\mathrm{t}=2.77 \\
\mathrm{p}<0.05\end{array}$ \\
\hline
\end{tabular}

\subsection{Influence of gender on negative advertising responses}

The Student-Fisher t-test shows a statistically significantly more negative advertising response in men $(\overline{\mathrm{x}} 2=1.71)$ than in women $(\overline{\mathrm{x}} 1=1.53)$, when the advertisement does not 
present complete information about the product $(\mathrm{t}=3.20, \mathrm{p}<0.01)$, Table 4 . Gender determines a more negative advertising response in men $(\overline{\mathrm{x}} 2=1.71)$ than in women $(\overline{\mathrm{x}} 1=$ $1.53)$ and in the case when respondents consider that advertising does not clearly present the qualities of the product $(\mathrm{t}=3.20, \mathrm{p}<0.01)$. Similarly, the subjective judgments that advertising is meaningless and incomprehensible provoked a statistically significantly more negative advertising response in men $(\overline{\mathrm{x}} 2=1.72)$ than in women $(\mathrm{x} 1=1.60 ; \mathrm{t}=2.10, \mathrm{p}<0.05)$, Table 4. Significantly more negative response in men $(\overline{\mathrm{x}} 2=1.81)$ is found in disappointment with the purchased product, compared to women $(\overline{\mathrm{x}} 1=1.58)$, who form a less negative advertising response in disappointment with the purchase.

As descriptors of frustration after buying a mobile product, men report feelings of anger, insecurity and even robbery, while women most often claim to be confused. The discrepancy between the advertised and the actual characteristics of the product could probably lead to a strongly negative advertising response in women, after the imposition of more disappointments.

Table 4. Influence of gender on negative advertising responses.

\begin{tabular}{|c|c|c|c|}
\hline Dependent Variable & $\begin{array}{c}\text { Independent } \\
\text { Variable }\end{array}$ & $\overline{\mathbf{x}}$ & $\mathbf{t}$ \\
\hline 1. The advertisement does not provide complete product & Female & 2.54 & $\mathrm{t}=3.20 ;$ \\
information & Male & 2.72 & $\mathrm{p}<0.01$ \\
\hline 2. The advertisement does not clearly present the & Female & 2.39 & $\mathrm{t}=3.20 ;$ \\
qualities of the product & Male & 2.17 & $\mathrm{p}<0.01$ \\
\hline \multirow{2}{*}{ 3. The advertisement is meaningless / incomprehensible } & Female & 2.37 & $\mathrm{t}=2.10 ;$ \\
& Male & 2.26 & $\mathrm{p}<0.05$ \\
\hline \multirow{2}{*}{ 4. Disappointment with the purchased product } & Female & 2.09 & $\mathrm{t}=2.48 ;$ \\
& Male & 2.27 & $\mathrm{p}<0.05$ \\
\hline
\end{tabular}

\section{Analysis and Discussion}

The results of the study confirm the working hypothesis that the gender of young people using mobile products and services influences the advertising response to advertisements of mobile products and services. Consistent empirical confirmation is found in some basic hypotheses of the Selective model of information processing in advertising messages: first for objectivity in the processing of information by men and subjectivity in the processing of information by women; secondly, selectivity in the perception of the attributes of the product by men and, more generally, by women; and thirdly, a stronger willingness to use new products by women than by men.

The results show that the men covered in the study attach the greatest importance to the objective attributes of the product and its functionality. In the present study, this is the only reason why men form a more positive advertising response than women. In addition, the study found that men tend to generate statistically significantly more negative advertising responses than women when there is a lack of objectivity in advertising messages insufficient, unclear, meaningless, or incomprehensible information.

The explanation for this result can be found in the hypothesis of a selective model that men focus on the main message of an advertisement [4], by assimilating mainly explicit signals of objective, material, visible attributes of product [6-7, 13, 29-30], which is the most important reason for a positive advertising response [3, 6, 21-23, 27]. According to Arcand and Nantel, for more complex products, providing a strong message that visually summarizes the main attributes and advantages of the product would be suitable for heuristic processing of men.

It is also interesting to note that the pleasure of using the product determines a statistically significantly lower positive response in men than in women, but the frustration with the 
product determines a stronger negative response in men than in women. This is probably due to the fact that men process messages linearly, with a strong focus on tasks and goal achievement $[4,12]$. Thus, any obstacle to the achievement of goals and objectives can lead to greater frustration in men, which will induce their more negative advertising response to disappointment with the product, compared to women.

In general, the group of men declare more negative impressions from the advertisements of mobile products, when the advertising messages are not clearly focused on the functionality and applicability of the product, which is expected to solve the problem, whatever that product is.

All three characteristics support the hypothesis of the selective model that women will respond more holistically, and that they respond to subjective advertising messages more than men [6] (Darley and Smith, 2013). Demonstration of the product provides long-term exposure of the advertised product, creating conditions for the perception of more signals necessary for the complete processing of information, which women as complete processors need more than men who perceive advertising as selective processors. [7-8, 36, 6-7, 13, 21, 29]. In most cases, the demonstrations also create a more intense emotional context, as advertisers express pathos, admiration and amazement at the product's qualities. It is possible for emotional contagion to occur in the observer group in response to this emotional context, especially in women [3, 6, 21-23]. Mobile operators' marketers should keep in mind that product demonstration would be an effective approach in attracting a female audience.

In accordance with the selective model, women pay more attention to advertising, which has an entertaining nature, evokes pleasure and emotions from stimuli such as pleasant music, beautiful characters or a romantic story. In general, they are more attracted to the hedonistic feelings in advertising [1]. The experience of pleasure is generally a very strong predictor of advertising influence, so the presence of entertainment components, although they cannot guarantee the effectiveness of sales effectiveness, can stimulate advertising responses [3839] e.g., in search behaviors for more and more reliable information about the advertised products. The present study shows that in respondents of both sexes the positive response to the entertainment effects in advertising is strongly proportional to the satisfaction with the use of purchased products. It can be assumed that when the quality of mobile products is associated with entertainment not only in advertising but also in their actual use, subsequent advertising messages elicit positive responses, regardless of gender.

There is a one-way gender impact on negative advertising responses. The group of men is more strongly influenced by the lack of information about the functionality of the product, due to which men form more negative advertising responses than women. In addition, women seem to find it easier to overcome the frustration of using a mobile product in their response to subsequent advertisements. One possible explanation to be examined in future studies is the gender difference found in the selective model in the more common preference for women to try new brands and products, while men more often prefer to stick to well-known brands. It can be hypothesized that the lower sensitivity of women to disappointment with the product, and their weaker negative advertising response after disappointment, compared to men, is due to their greater willingness to redirect their interest to another, new product. It is therefore easier to persuade women to try a new product than to persuade men.

\section{Conclusion and Summarized Inferences}

The authors hope that this study will enrich the scarce data on gender differences in the responses to advertisements of products and services, on the gender comparison with a positive but also a negative response to advertising messages from young consumers. The results of the empirical study show that gender as an independent variable significantly 
differentiates the responses of participants to the factors positive and negative response to advertising messages in the specific economic sector of mobile services.

Two of the main hypotheses of the Selective Model for Gender Differences in Information Processing, related to the selective processing of objective advertising messages by men and more comprehensive processing of subjective advertising messages by women, are confirmed.

In general, men respond positively to advertisements containing rich information, clear messages, and functional solutions, while women respond positively to the emotional context of advertisements, longer exposure and direct contact with the products.

The results of the study can contribute to the enrichment of scientific information on the topic with several empirical hypotheses:

- Women form positive responses to a larger number of signals in advertising, while men form negative responses to a larger number of signals in advertising messages.

- Satisfaction turns out to be a very important factor for advertising responses for both sexes. For men, satisfaction with the actual use of a mobile product is lower than for women, and men's frustration with a mobile product is higher than for women.

- Women are less frustrated with mobile products, probably because of their willingness to try different new products in the future

It would be useful to make gender research part of marketing research to establish the effectiveness of advertising influence and personalize the content and design of advertising messages to attract users of both sexes.

The question of transforming negative advertising responses into positive ones remains important. Such studies can help formulate some guidelines: In order to attract a group of men, the content of advertisements should be structured to match the male selective style of processing, which is focused on personal needs, and key information should be visible and easily accessible. Too descriptive information would be unattractive to men. On the other hand, the creation of advertisements that attract women should facilitate relational processing through a combination of product attributes and subjective elements of advertising, and the information should also represent the context in which the products are used.

When advertising messages correspond in content and structure to gender differences, increased consumer interest in products and greater trust in companies should be expected.

\section{Limitations of the Study:}

The study does not examine the types and amount of cognitive responses, the requirements of the tasks facing the respondents and the heuristics used. The specifics of the media channels through which the advertising impact is carried out are not taken into account. Socialization differences between the respondents were also not studied, which could affect the styles of information processing.

\section{Future Searches:}

Future research searches may focus on further age expansion of the sample, to further test the formulated empirical hypotheses. It would be useful to include other demographic characteristics such as age, education, financial and marital status, occupational employment, as well as features of primary socialization, which could be factors for systematic variations in information processing strategies.

\section{References}

1. R. Johnson, Gender Differences in Advertising Between Men and Women, (London: Pearson Education Limited, May 2021)

2. C. O. Sam, C. K. Anthony, S. G. Bashar, Int. J. Mark. Stud., 2(1), 3-12 (2010)

3. W. Kraft, J. M. Weber, Int. J. Bus. and Soc. Scie., 3(21), 247-253 (2012) 
4. K. Sheehan, Controversies in Contemporary Advertising, (SAGE Knowledge, 2012)

5. M2W. Marketing to Millennial Women, 15th Annual Conference, 16-17 October 2019, New York City, https://m2w.biz/fast-facts

6. W.K. Darley, R. E. Smith, J. Advert., 24, 41-56 (2013)

7. L. D. Wolin, J. Advert. Res., 43(1), 11-129 (2003)

8. J. Meyers-Levy, D. Sternthal, J Mark Res, 28(1), 84-96 (1991)

9. H. Eagly, G.Carli, L. L. Canri, Psychological Bulletin, 90, 1-20 (1981)

10. V. Rutledge -Shields, Ann. Int. Commun. Assoc., 20(1), 71-109, (2016)

11. M. E. Kite, K. Deaux, RRSP: Representative Res. in Soc. Psych., 16, 38-43 (1987)

12. M. Arcand, J. Nantel, J. Theor. Appl. Electron. Commer. Res., 7(2), 106-120 (2012)

13. J. Meyers-Levy, Gender differences in information processing: A selectivity interpretation, in Cognitive and Affective Responses to Advertising, (P. Cafferata and A. Tybout, Eds., Lexington, MA: Lexington Books, 219 - 260, 1989)

14. S. Putrevu, Academy of Mark. Sci. Rev., 10, 1-12 (2001)

15. D. Bakan, The Duality of Human Existence, (Chicago: Rand McNally, 1966)

16. R. Carlson, J Consult Clin Psychol, 37(2), 267-277 (1971)

17. R. Carlson, J Soc Issue, 28(2), 17-32 (1972)

18. P. Jr. Costa, A. Terracciano, R. R. McCrae, J Pers Soc Psychol, 81(2), 322-331 (2001)

19. A. Feingold, Psychological Bulletin, 116(3), 429456 (1994)

20. J. Van Grove, How Women Use the Web, (Mashable Social Media, 2010)

21. J. Cummings, Is there a difference between marketing to men and marketing to women?, (2017), [Online], https://blog.ideacafe.com/there-difference-betweenmarketing-men-and-marketing-women

22. A. Baker, Gender Differences in Decision Making, (2012), [Online], http://www.decision-makingconfidence.com/gender-differences-in-decisionmaking.html [Accessed: 9 Sept. 2012]

23. R. J. Moore, He Said, She Said: Marketing to the Sexes, Dynamic Graphics \& Create Magazine, (2012), [Online], http://dynamicgraphics.com/dgm/Article/28851/index.html [Accessed: 3 Sept. 2012]

24. J. A. Edell, R. Staelin, APA Psyc Info, 10(1), 45-61 (1983)

25. M. B. Holbrook, J Market Res, 15(4), :545-556 (1987)

26. B. Reeves, C. K. Atkin, The Effects of Televised Advertising on Mother-Child Interactions at the Grocery Store, (ERIC Clearinghouse, 1979)

27. D. M. Broverman, L.E. Klaiber, Y. Kobayashi, Psychol Rev, 75(1), 23-50, (1968)

28. T. A. Holland, 7 Powerful Insights for Marketing to Women, (2006), [Online], https://startupnation.com/start-your-business/plan-your-business/marketing-to-women/ [Accessed: May 2021]

29. J. Meyers-Levy, D. Maheswaran, J. Consum. Res., 18(1), 63-70 (1991)

30. F. Popcorn, L. Marigold, EVEolution: The Eight Truths of Marketing to Women, (Hyperion Books, 234-257, 2000)

31. J. Margolis, A Fisher, F Miller, IEEE Technology and Society Magazine, 18(4) Winter, 13-20 (2000)

32. D. Kimura, Sex and Cognition. Cambridge, (MA: MIT Press, 2000).

33. H. Eagly, Am. Psychol, 64(8), 644-658 (2009) 
34. L. Cahill, Scientific American, 292(5), 40-47 (2005)

35. M. L. Carsky, M. E. Zuckerman, GCB - Gender and Consumer Behavior, 1, UT: Association for Consumer Research, 43-52 (1991)

36. K. Kempf, R. Palan, L. Laczniak, Adv Consum Res., 24, 443- 49 (1997)

37. J. C. Nunnally, Psychometric theory, (2nd ed., New York, NY: McGraw-Hill, 1978)

38. W. Gordan, Ad Pre-Testing Works - Does It, Admap, 349, 57-60 (1995)

39. R. Heath, The Hidden Power of Advertising, (Admap Monograph., Henley-onThames, WARC, 2001)

40. J. Joy, Customer Communication Styles, (2012), [Online], https://ezinearticles.com/?3Customer-Communication-Styles\&id=239888 [Accessed: May 2021]

41. K. Anderson, Consumers Want Simplicity, [Online], http://www.20-first.com/1601-0consumerswant-simplicity.html [Accessed: 8 Sept. 2012]

42. M. Levit, The Difference Between Men and Women, (2012), [Online], http://www.evancarmichael.com/Branding/69/The-Difference-Between-MenandWomen.html [Accessed: 10 Sept. 2012]

43. M. L. Carsky, M. E. Zuckerman, GCB - Gender and Consumer Behavior, 1, UT: Association for Consumer Research, 43-52 (1991)

44. M. L. Carsky, M. E. Zuckerman, GCB - Gender and Consumer Behavior, 1, UT: Association for Consumer Research, 43-52 (1991)

45. D. Sutton, Globalizing ideal beauty: How female copywriters of the J. Walter Thompson Advertising Agency redefined for the twentieth century, (New York, NY: MacMillan Palgrave, 2009)

46. J. Meyers-Levy, Gender differences in information processing: A selectivity interpretation, in Cognitive and Affective Responses to Advertising (P. Cafferata and A. Tybout, Eds., Lexington, MA: Lexington Books, 219 - 260, 1991)

47. Zh. Yankova, Determinanti v dostŭpa do obrazovanie na detsa i uchenitsi sŭs spetsialni obrazovatelni potrebnosti, (Plovdiv: Universitetsko izdatelstvo „Paisiǐ Khilendarski“, ISBN: 978-619-202-513-7, 2019) 